\title{
The Influence of Swine-Waste Biochar on the Early-Age Characteristics of Cement Paste
}

\author{
Andrea Nana Ofori-Boadu*, Rico Kelley**, Frederick Aryeetey***, \\ Elham Fini****, Paul Akangah***** \\ *(Department of Built Environment, North Carolina A \& T State University, USA) \\ **(Department of Built Environment, North Carolina A \& T State University, USA) \\ *** (Joint School of Nanoscience and Nanoengineering, North Carolina A \& T State University, USA) \\ ****(Department of Civil, Architectural, and Environmental Engineering, North Carolina A \& T State \\ University, USA \\ **** (Department of Mechanical Engineering, North Carolina A \& T State University)
}

\begin{abstract}
The purpose of this research was to investigate the influence of swine-waste biochar (SB) on the early-age characteristics of cement pastes. Using a water/binder ratio of 0.28 , SB modified cement pastes were analyzed using Scanning Electron Microscopy (SEM), Fourier Transform Infrared Spectroscopy (FTIR), flow, and Vicat setting tests. Notably, SB reduced the flow and initial setting times of SB modified cement pastes. Due to its porous and negatively charged surfaces, capillary water was adsorbed into the pores of the carbonaceous SB and this reduced the flow of the SB modified cement pastes. Furthermore, it is suspected that the reductions in initial setting times may have been because with the addition of water to the dry $\mathrm{SB} /$ cement binder mix, chemical reactions between the calcium cations from Portland cement and carboxylate anions from SB resulted in the development of Calcium Polycarboxylate Salts (C-P-S). Improvements in the properties of SB could enhance its applications in rapid-setting and flow-reducing concrete.
\end{abstract}

Keywords: cement, biochar, swine-waste, carboxylates, setting, flow.

\section{INTRODUCTION}

World structures and global economies are highly dependent on cement production. However, cement production continues to present significant environmental challenges due to its energy-intensive production processes, greenhouse gas emissions and air pollutants [1][2]. The cement production industry in the United States is responsible for approximately $1 \%$ of all carbon dioxide emissions [3]. Considering these unacceptable levels of emissions, [2] recommended that the cement industry seriously consider using waste materials in cement production processes to minimize environmental degradation. [4] noted that animal wastes are increasingly being recognized as viable bioresources due to their rich carbon composition. It is in this context that swine manure or swine waste presents a unique opportunity to develop a bio-modified cementitious material with potential environmental and economic benefits.

Using data from the U.S. Department of Agriculture (USDA), the U.S. General Administration Office [5] estimated that in 2002 alone, five North Carolina counties had in excess of 7.5 million hogs; and they produced as much as 15.5 million tons of manure in that year alone. Commercial hog operations have led to excessive swine waste storage lagoons, which have resulted in a myriad of environmental problems [6]. These devastating environmental impacts from swine and other animal wastes has spurred ongoing research to transform wastes to useful applications. Recently, several researchers have focused on the development of biochar derived from agricultural residues such as animal waste and plants [4][7][8].

Biochar is a carbon rich substance produced by using pyrolysis to convert biomass to biochar. Pyrolysis is a thermochemical process used to process biomass at elevated temperatures without the presence of oxygen. Biochar is typically a black solid residue or by product that primarily consists of a porous network of carbonates and/or aromatic carbon (Herbert, Hosek, and Kripalani, 2012). Several researchers have elaborated on the feedstock, source, production temperatures, particle sizes, surface area, negatively charged surfaces, $\mathrm{pH}$, porosity, water uptake, adsorption and recalcitrant nature, and cation exchange properties of biochar [7][9][10]. As biochar ages, the concentration of basic sites reduces due to oxidative interactions and this results in the formation of functional groups such as carboxylic and carbonyl groups [9]. The physiochemical properties of SB have been studied by several researchers [4][8][11].

Although traditionally biochar is used in agriculture and livestock farming, it is now being seriously considered for applications in the 
construction industry [12][13]. [12] emphasized that biochar has excellent insulating properties, improves air quality, soaks moisture, protects from radiation and allows buildings to be turned into carbon sinks. [14] found that SB improved dispersion and liquid retention in asphalt concrete, while enhancing oxidation resistance. Biochar in buildings could reduce environmental degradation [12].

\subsection{Purpose of the Study}

The main purpose of this research was to investigate the influence of $\mathrm{SB}$ on the early-age characteristics of SB-modified cement pastes. Specifically, the research objectives focused on influence of SB on the setting and flow of cement pastes. Considering the dilution effect of partially replacing cement with $\mathrm{SB}$, it was hypothesized that the partial replacement of Portland cement with SB would influence the flow and setting of cement pastes. However, the extent of this influence is yet to be understood as no previous studies are known to have conducted this investigation.

\section{EXPERIMENTAL MATERIALS AND METHODS}

Type 1/1A normal Portland cement as specified by the American Society for Testing Materials (ASTM C-150) was purchased from a Home Depot store in North Carolina. It had a specific gravity of 3.15 and a $\mathrm{pH}$ between 12 and 13 . Portable water was obtained from the faucet at a sink in the Soils Laboratory at North Carolina Agricultural \& Technical State University. SB is a black carbon-rich powdery substance which is a residue from a thermochemical process used to convert swine manure into bio-oil [15]. It was obtained from the Sustainable Infrastructure Material (SIM) lab at North Carolina Agricultural \& Technical State University. Table 1 shows the mix design for the cement pastes used in this research study.

Table 1. Mix Design

\begin{tabular}{cccc}
\hline $\begin{array}{c}\text { Mix } \\
\text { Design }\end{array}$ & $\begin{array}{c}\text { Cement } \\
(\%)\end{array}$ & $\begin{array}{c}\text { SB } \\
(\%)\end{array}$ & $\begin{array}{c}\text { Water/Binder } \\
\text { Ratio }\end{array}$ \\
\hline SB0.00 & 100.00 & 0.00 & 0.28 \\
SB1.25 & 98.75 & 1.25 & 0.28 \\
SB2.50 & 97.50 & 2.50 & 0.28 \\
SB5.00 & 95.00 & 5.00 & 0.28 \\
SB10.00 & 90.00 & 10.00 & 0.28 \\
\hline
\end{tabular}

Following the mix design for the five different specimens listed in Table 1, the different components (SB, cement, and water) were weighed. The next step involved a dry binder mixing process which involved SB and cement. SB was manually mixed with cement until a uniform binder mix was obtained. The mixing forces generated were used to overcome the cohesive interparticle van der Waals' forces present in SB clusters. Furthermore, electrostatic interactions between the negatively charged SB and cement enhanced SB adsorption on to cement particle surfaces, thereby creating a more uniform mix [16]. Consequently, the dry mixing process reduced the agglomeration of SB, enhanced its dispersion in cement powders, and improved the uniformity of the dry binder mix. After the dry binder mixing, the ASTM wet mechanical mixing process (ASTM C305-14) for cement pastes was followed [17].

The ASTM C1437 standard test for the flow of hydraulic cements was used to assess the impact of SB on the flow of cement pastes [18]. After placing the specimens on the flow table, the flow table was dropped 25 times. Four different base diameter (d) readings of the spread cement paste specimen were taken at the four lines scribed on the flow table top. The average base diameter $\left(d_{a}\right)$ was the sum of the four base diameters (d) divided by 4 . The Flow Percent $(\mathrm{F})$ is the resulting increase in the average base diameter $\left(\mathrm{d}_{\mathrm{a}}\right)$ of the tamped specimen, expressed as a percentage of the original inside base diameter (D) of the mold (Equation 1).

$\mathrm{F}=\left(\mathrm{d}_{\mathrm{a}}-\mathrm{D}\right) / \mathrm{D} \times 100$

Equation 1

The ASTM C191 standard test was used for determining the time of setting of the cement paste specimens using the Vicat Needle Method [19]. The initial setting time was recorded when a $25 \mathrm{~mm}$ needle penetration was obtained.

The Fourier Transform Infrared (FTIR) spectroscopy test was conducted at room temperature to chemically characterize cement, swine-waste biochar, and cement pastes. FTIR tests were completed with a Varian 670 FTIR Spectrometer. Using wave numbers ranging from $4000 / \mathrm{cm}$ to $500 / \mathrm{cm}$, the spectra of the specimens was used to detect the functional groups in the specimens. The Scanning Electron Microscope (SEM) - Carl Zeiss Auriga SEM-FIB Crossbeam Workstation was used to examine the microstructure of specimens. The specimens were placed on carbon conductive tabs on stub mounts, and then positioned in the SEM equipment for imaging. The SEM micrographs were used to describe the microstructure of specimens. Energy Dispersive Spectroscopy (EDS) analysis was used to provide elemental analysis of the specimens. 


\section{RESULTS AND DISCUSSIONS}

\subsection{SEM and EDS of SB}

The SEM micrographs of SB clusters showed its rough exterior surfaces. The varying sizes of the amorphous SB clusters are shown in Figure 1.

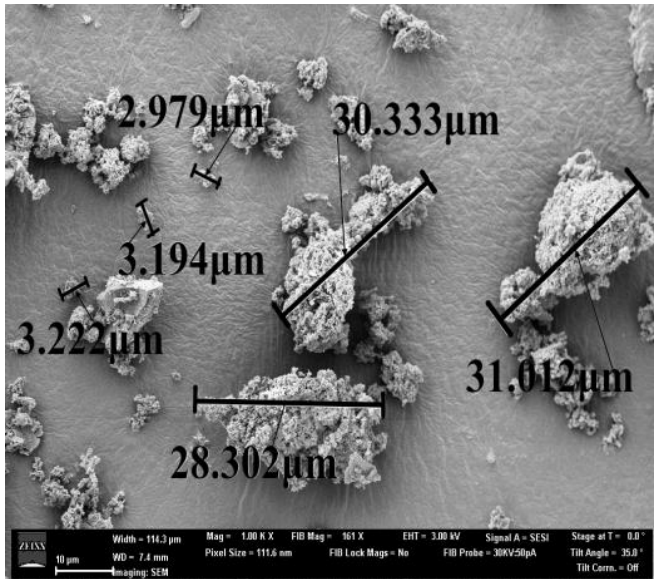

Fig. 1. SEM micrographs of SB clusters,

1000x. (SEM image is by Dr. Kyle Nowlin)

The morphological SEM micrographs of the SB cluster showed in Figure 2 confirmed that SB has porous surfaces. The white clusters represent SB particles drawn together by van der Waals' interparticle cohesive forces. The darker areas on the micrographs represent the pores within the SB cluster. The high levels of porosity found on the negatively-charged surfaces of biochar are likely to increase the water adsorption characteristics of SB.

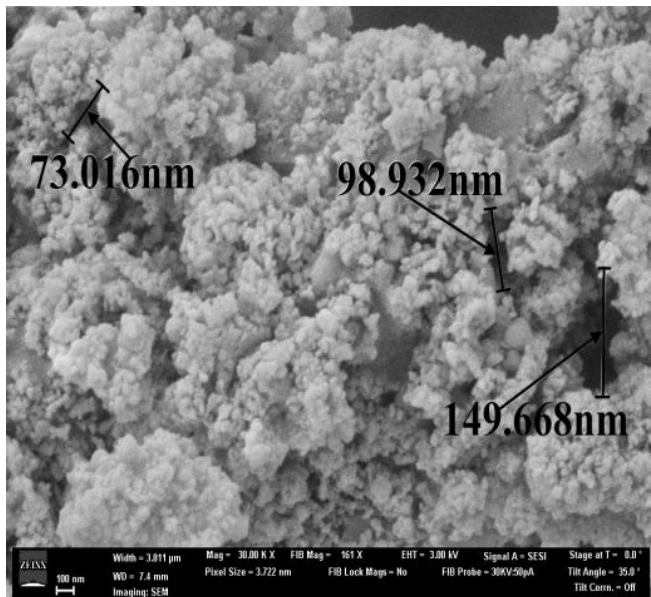

Fig. 2. SEM micrographs of SB cluster, $30,000 x$. (SEM image is by Dr. Kyle Nowlin)

SEM-EDS elemental analysis of SB showed the following key elements: carbon $(54.02 \%)$; oxygen $(30.60 \%)$; calcium $(5.00 \%)$; silicon $(0.95 \%)$; and aluminum $(0.34 \%)$.

\subsection{FTIR spectra of SB and cement}

The FTIR spectra (Figure 3) showed a sharp doublet at $2848 \mathrm{~cm}^{-1}$ and $2913 \mathrm{~cm}^{-1}$. This was for $\mathrm{C}-\mathrm{H}$ bonds in alkanes in SB. The doublet feature at $2330 \mathrm{~cm}^{-1}$ and $2360 \mathrm{~cm}^{-1}$ corresponded to the presence of carbon dioxide, adsorbed within the SB micropores. The asymmetrical stretch at $1564 \mathrm{~cm}^{-1}$ was assigned to aromatic $\mathrm{C}=\mathrm{C}$ bonds and $\mathrm{C}=\mathrm{O}$ bonds in carboxyl groups in SB. The asymmetric stretch centered around $1465 \mathrm{~cm}^{-1}$ for SB was likely for $\mathrm{C}-\mathrm{H}$ bonds. Lastly, the $\mathrm{C}-\mathrm{O}$ stretching bonds as demonstrated by the doublet feature observed at $1060 \mathrm{~cm}^{-1}$ and $1002 \mathrm{~cm}^{-1}$ was assigned to alcohols, ethers, carboxylic acids, and esters. These results are in agreement with [21]. The EDS and FTIR results strongly suggested the presence of carboxyl groups in SB.

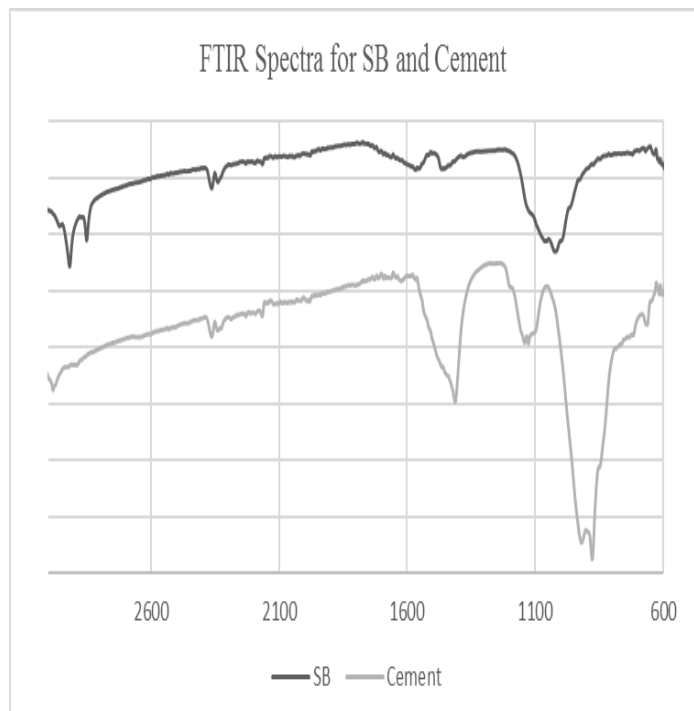

Fig. 3. FTIR Spectra for SB and cement

Strong FTIR responses for cement at 1415 $\mathrm{cm}^{-1}$ and $1145 \mathrm{~cm}^{-1}$ confirmed the presence of carbonates and sulfates in Portland cement. The doublet feature at $920 \mathrm{~cm}^{-1}$ and $875 \mathrm{~cm}^{-1}$ was assigned to the $\mathrm{Si}-\mathrm{O}$ asymmetric stretching vibrations, and characterized the presence of tricalcium silicates and dicalcium silicates. These results are in agreement with [22].

\subsection{Flow of SB modified cement pastes}

The presence of SB resulted in reductions in the flow of cement pastes. Figure 4 demonstrated that SB10.00 had the least flow percent $(47 \%)$, while SB0.00 had the highest flow percent $(77 \%)$. The consistent reduction in cement paste flow with increments in SB replacement percentages provided a strong indication that SB increased the viscosity of cement pastes, and this in turn reduced the flow of cement pastes. 
The reduction in the flow of cement pastes with SB may be attributed to SB's carboxyl functional groups that generated negative charges on the porous surfaces of SB. As soon as the mixing water was added to the cement and SB binder mix, a portion of the capillary water was adsorbed into the pores on the surfaces of the carbonaceous SB. This was as a result of the electrostatic interactions between the positively charged hydrogen ions from water and the negatively charged $\pi$-electrons associated with the shared electron cloud from either the $\mathrm{C}=\mathrm{O}$ or the $\mathrm{C}=\mathrm{C}$ bonds in $\mathrm{SB}[23]$.

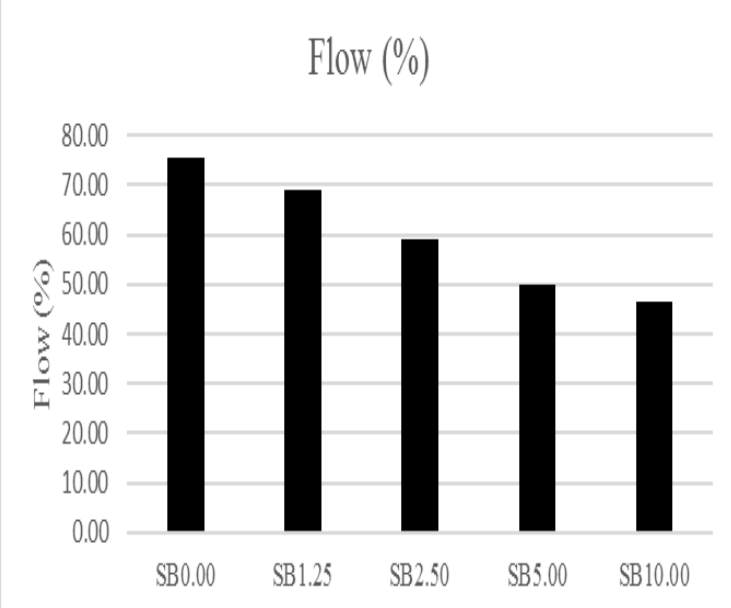

Fig. 4. Flow of cement pastes

Furthermore, due to its high surface areas and its high porosity, a pore-filling mechanism began and progressed within a short time as water was sucked into SB pores through capillary forces that attracted water into SB pores. The retention of a portion of the mixing water in the SB pores reduced the available mixing water. Consequently, higher replacement percentages of SB resulted in further reductions in the capillary water. This resulted in the closer packing of binder particles, as there were reductions in the inter-particle distances. Consequently, cement and SB particles were positioned much closer together, thereby increasing viscosity and reducing the flow of the SB modified cement pastes.

At a constant water/binder ratio, as the replacement percentage of SB was increased and that of cement was decreased, the flow of cement paste was reduced. As such, cement pastes with higher percentages of $\mathrm{SB}$ will require higher water/binder ratios in order to increase the availability of mixing water. This should improve flow and workability. This finding was in agreement with [3], who emphasized that the high carbon content of plant-based biochar in mortar increased the demand for water and thus affected workability. This flow-reducing characteristic of cement pastes modified with SB presents the potential for developing flow-reducing binders as suggested by [3].

\subsection{Setting of SB modified cement pastes}

The presence of SB reduced the initial setting times of cement pastes; however, the setting times for all the cement pastes with SB in this study were still within the acceptable limits prescribed by ASTM. Figure 5 showed a consistently negative relationship between SB replacement percentages and the initial setting times of SB modified cement pastes. This demonstrated that the setting times of cement pastes decreased with increments of SB in the cement pastes. With the $10 \%$ SB replacement, the initial setting time of SB10.00 encountered a $30 \%$ reduction when compared to SB0.00. This inferred that the typical dormant period of cement paste hydration was reduced, possibly, because of chemical reactions that may have occurred following the addition of SB.

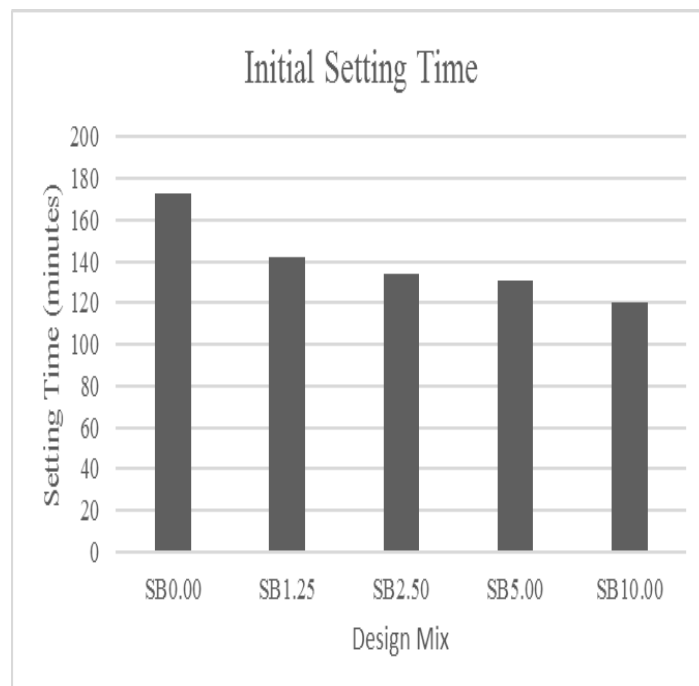

Fig. 5. Initial setting times of cement pastes

The difference between the initial setting times of cement pastes with SB and the control cement pastes may be attributed to the development of Calcium Polycarboxylate Salts (C-P-S). This was initiated when water was added to the dry cement and SB binder mix. It is suspected that chemical reactions involving carboxylate anions from SB and calcium cations from cement resulted in the formation of C-P-S. C-P-S is known to have rapid setting cementitious characteristics and is commonly used in dentistry [24][25].

Figure 6 shows the spectra for SB10.00 at ages 1 minute and 180 minutes following the addition of mixing water to the dry SB/cement binder mix. The presence of C-P-S is confirmed by the shifts shown in this FTIR spectra. These important shifts provided some insights into the 
chemical reactions that occurred within cement pastes with SB.

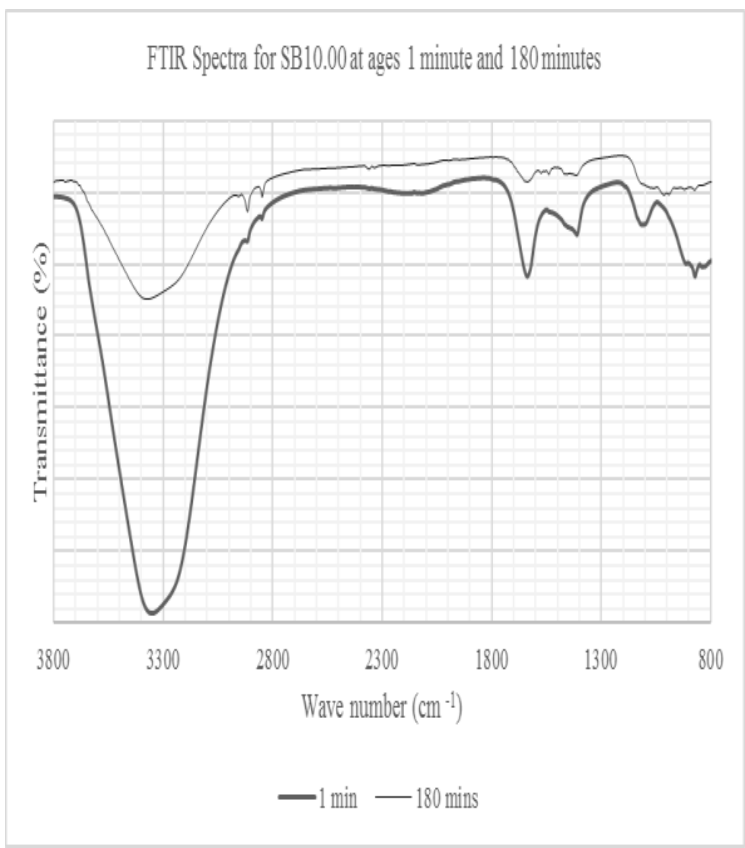

Fig. 6. FTIR spectra of SB10.00

Compared with the 1-minute spectrum, a reduction in the $\mathrm{O}-\mathrm{H}$ stretch $\left(3350 \mathrm{~cm}^{-1}\right)$ was observed in the 180-minute spectrum. This occurred because capillary water was consumed during the chemical reactions that resulted in the development of both Calcium-Silicate-Hydrates $(\mathrm{C}-\mathrm{S}-\mathrm{H})$ and Calcium-Polycarboxylate-Salts (C-P-S). Furthermore, a reduction in the stretch at $1630 \mathrm{~cm}^{-1}$ and emerging weak stretches at $1571 \mathrm{~cm}^{-1}, 1538 \mathrm{~cm}^{-}$ 1 and $1470 \mathrm{~cm}^{-1}$ were observed in the 180 -minute spectrum. These were attributed to the vibrations of carboxylate anions that have reacted with calcium cations to form C-P-S [26]. Slightly intensified C-H bonds for alkanes were observed at $2917 \mathrm{~cm}^{-1}$ and $2850 \mathrm{~cm}^{-1}$. This is because with the reduction of capillary water, it was easier for the FTIR equipment to detect the presence of $\mathrm{C}-\mathrm{H}$ bonds. Furthermore, the emergence of the stretch at $1010 \mathrm{~cm}^{-1}$ was assigned to the $\mathrm{C}-\mathrm{O}$ stretching in C-P-S. These results were in agreement with various researchers who have investigated polycarboxylate salts, particularly in the field of dentistry [26-29]

Together with the EDS results, these FTIR results demonstrate the development of C-P-S which reduced the setting times of $\mathrm{SB}$ modified cement pastes. This is because the development of C-P-S resulted in the creation of additional nucleation or seeding sites that enhanced the precipitation of more hydrates in the pore space. [30] explained that additional nucleation sites form within the pore spaces, while the typical cement hydration nucleation sites for C-S-H occur only on or near the cement particle spaces. Drawing from these results, SB has the potential for rapid-setting concrete applications.

Future research should investigate the impact of SB on the compression strength and surface hardness of SB modified cement pastes.

\section{CONCLUSION}

The research findings revealed that swine-waste biochar influenced the early-age characteristics of SB modified cement pastes:

- The porous and negatively-charged carbonaceous surfaces of swine-waste biochar resulted in its adsorption of capillary water and this reduced the flow of the swine-waste biochar modified cement pastes.

- With the addition of water to the dry swinewaste biochar/cement binder mix, chemical reactions between carboxylate anions from swine-waste biochar and calcium cations from Portland cement resulted in the development of Calcium-Polycarboxylate-Salts.

- The development of Calcium-PolycarboxylateSalts reduced the initial setting times of cement pastes modified with swine-waste biochar.

Considering its influence on the early-age characteristics of cement pastes, improvements in the properties of swine-waste biochar would allow its use in rapid-setting and low-flow concrete applications. In view of the fact SB is a waste product with carbon sequestration properties, its development could generate both economic and environmental benefits.

\section{ACKNOWLEDGEMENTS}

Primary funding for this research was through a faculty start-up award provided by North Carolina A \& T State University through a United States Department of Education - Title III initiative. 


\section{REFERENCES}

[1]. Uwasu, M., Hara, K. \& Yabar, H. World cement production and environmental implications. Environmental Development (10), 2014, 36-47.

[2]. World Business Council for Sustainable Development. The cement sustainability initiative. Retrieved on December 26, 2016 from http://www.wbcsdcement.org/pdf/CSIRecyclingConcrete-FullReport.pdf

[3]. Choi, W. C., Yun, H. D., and Lee, J. Y. Mechanical properties of mortar containing bio-char from pyrolysis. Journal of the Korea Institute for structural maintenance and inspection. 16(3), 2012, $67-74$.

[4]. Tsai, W.-T., Liu, S.-C., Chen, H.-R., Chang, Y.-M., and Tsai, Y.-L. (2012). Textural and chemical properties of swine-manure-derived biochar pertinent to its potential use as a soil amendment. Chemosphere, 89, 2012, 198 203.

[5]. U.S. Government Accountability Office (GAO) (2008). Concentrated Animal Feeding Operations. Retrieved on November 1, 2016 fromhttp://www.gao.gov/new.items/d08944.p df

[6]. Aneja, V. P., Chauhan, J. P. and Walker, J. T. Characterization of atmospheric ammonia emissions from swine waste storage and treatment lagoons. Journal of Geophysical Research, 105(D9), 2000, 535 - 545.

[7]. Jindo, K. Mizumoto, H., Sawada, Y. , Sanchez-Monedero, M. A. and Sonoki, T. Physical and chemical characterization of biochars derived from different agricultural residues. Biogeosciences, 11, 2014, 66136621.

[8]. Cantrell, K. B., Hunt, P.G., Uchimiya, M., Novak, J. M., and Ro, K. S. Impact of pyrolysis temperature and manure source on physiochemical characteristics of biochar. Bioresource Technology, 107, 2012, 419 428.

[9]. Herbert, L., Hosek, I., and Kripalani, R. The characterization and comparison of biochar produced from a decentralized reactor using forced air and natural draft pyrolysis. Retrieved on December 26, 2016 from http://digitalcommons.calpoly.edu/cgi/viewc ontent. .gi? article $=1047 \&$ context $=$ matesp

[10]. Gray, M., Johnson, M. G., Dragila, M. I., and Kleber, M. (2014). Water uptake in biochars: The roles of porosity and hydrophobicity. Biomass and bioenergy, 61, 2014, $196-205$.
[11]. Cao, X., Ro, K. S., Chappell, M., Li, Y., and Mao, J. (2011). Chemical structures of swinemanure chars produced under different carbonization conditions investigated by advanced solid-state C Nuclear Magnetic Resonance (NMR) spectroscopy. Energy Fuels, 25, 2011, 388 - 397.

[12]. Schmidt, H. J. (2013). The Use of Biochar as a Building Material-Cities as Carbon Sinks. ithaka-journal.net. 2013. Retrieved on January 2, 2017 from http://www.ithakajournal.net/pflanzenkohle-zum-hauserbauen-stadte-als- kohlenstoffsenken?lang=en

[13]. Chen, W., Chen, M., and Zhou, X. Characterization of Biochar Obtained by CoPyrolysis of Waste Newspaper with HighDensity Polyethylene. BioResources, North America, 10(4), 2015, 8253 - 8267.

[14]. Walters, R., Begum, S. A., Fini, E. H. and Abu-Lebdeh, T. M. (2015). Investigating biochar as flow modifier and water treatment agent for sustainable pavement design. American Journal of Engineering and Applied Sciences. 8(1), 2015, 138 - 146.

[15]. Fini, E. H., Kalberer, E. W., Shahbazi, A., Basti, M., You, Z., Ozer, H., and Aurangzeb, A. Chemical characterization of biobinder from swine manure: sustainable modifier for asphalt binder. Journal of Materials in Civil Engineering, 23(11), 2011, 1506-1513.

[16] Zhang, Y. - R., Kong, X.-M., Lu, Z.-B., Lu, Z.-C., and Hou , S.-S. (2014). Effects of the charge characteristics of polycarboxylate superplasticizers on the adsorption and the retardation in cement pastes. Cement and Concrete Research, 67, 184-196.

[16]. American Standards for Testing Materials ASTM C305-14 Standard Practice for Mechanical Mixing of Hydraulic Cement Pastes and Mortars of Plastic Consistency, ASTM International, West Conshohocken, PA. 2014. http://dx.doi.org/10.1520/C030514

[17]. American Standards for Testing Materials. ASTM C1437-15, Standard Test Method for Flow of Hydraulic Cement Mortar. ASTM International, West Conshohocken, PA. 2015. Retrieved from www.astm.org

[18]. American Standards for Testing Materials (2013a). ASTM C191-13, Standard Test Methods for Time of Setting of Hydraulic Cement by Vicat Needle, ASTM International, West Conshohocken, PA, 2013. Retrieved from www.astm.org 
[19]. American Standards for Testing Materials (2013b). ASTM C642-13, Standard Test Method for Density, Absorption, and Voids in Hardened Concrete, ASTM International, West Conshohocken, PA, 2013, www.astm.org

[20]. Volland, W. (1999). Organic compound identification using infrared spectroscopy. Retrieved on January 17, 2017 from http://www.800mainstreet.com/irsp/eir.html

[21]. Horgnies, M., Chen, J. J., and Bouillon, C. Overview of the use of Fourier Transform Infrared Spectroscopy to study cementitious materials, WIT Transactions on Engineering Sciences, 77, 2013, $251-262$.

[22]. Nartey, O. D., and Zhao, B. Biochar preparation, characterization, and adsorptive capacity and its influence on bioavailability of contaminants: an overview. Advances in Materials Science and Engineering, 2014, 1 12.

[23]. Boyd, D., Clarkin, O. M., Wren, A. W., and Towler, M.R. (2007). Zinc-based polyalkenoate cement with improved setting times and mechanical properties. Acta Biomateriala, 4, 425-431.

[24]. Nair, A. V. (2014). Glass inomer cements. Retrieved on January 6, 2016 from http://www.slideshare.net/anoopdr1/gic35726496

[25]. Dickey, B., Price, R. and Boyd, D. (2016). Evidence of a complex species controlling the setting reaction of glass ionomer cements. Dental Materials, 32, 2016, 596 - 605.

[26]. Bertolini, M. J., Zaghete, M. A., Gimenes, R., and Padovani, G. C. Determination of the properties of an experimental glass polyalkenoate cement prepared from niobium silicate powder containing fluoride. Dental Materials, 24, 2008, $124-128$.

[27]. Young, A.M., Rafeeka, S.A., and Howlett J.A. FTIR investigation of monomer polymerisation and polyacid neutralisation kinetics and mechanisms in various aesthetic dental restorative materials. Biomaterials, 25, 2004, 823-833

[28]. Khashaba, R. M., Moussa, M, Koch, C., Jurgensen, A. R., Missimer, D. M., Rutherford, R. L., Chutkan, N. B., and Borke, J. L. Preparation, Physical-Chemical Characterization, and Cytocompatibility of Polymeric Calcium Phosphate Cements. International Journal of Biomaterials, 2011, 13.
[29]. Thomas, J.J., Jennings, H.M. and Jeffrey Chen, J. Influence of Nucleation Seeding on the Hydration Mechanisms of Tricalcium Silicate and Cement. The Journal of Physical Chemistry, 113 (11), 2009, 4327-4334 